in vivo $34: 2549-2559(2020)$

doi:10.21873/invivo.12072

\title{
Sarcopenia and Frailty in Chronic Liver Damage: Common and Different Points
}

\author{
HIROKI NISHIKAWA ${ }^{1,2 *}$, KAZUNORI YOH ${ }^{1 *}$, HIRAYUKI ENOMOTO $^{1}$, YOSHINORI IWATA ${ }^{1}$, \\ YOSHIYUKI SAKAI ${ }^{1}$, KYOHEI KISHINO ${ }^{1}$, YOSHIHIRO SHIMONO ${ }^{1}$, NAOTO IKEDA ${ }^{1}$, \\ TOMOYUKI TAKASHIMA $^{1}$, NOBUHIRO AIZAWA ${ }^{1}$, RYO TAKATA $^{1}$, \\ KUNIHIRO HASEGAWA ${ }^{1}$, TAKASHI KORIYAMA ${ }^{1}$, YUKIHISA YURI $^{1}$, \\ TAKASHI NISHIMURA ${ }^{1}$, SHUHEI NISHIGUCHI ${ }^{3}$ and HIROKO IIJIMA ${ }^{1}$ \\ ${ }^{1}$ Department of Internal Medicine, Division of Gastroenterology and Hepatology, \\ Hyogo College of Medicine, Nishinomiya, Japan; \\ ${ }^{2}$ Center for Clinical Research and Education, Hyogo College of Medicine, Nishinomiya, Japan; \\ ${ }^{3}$ Kano General Hospital, Osaka, Japan
}

\begin{abstract}
Aim: To elucidate the common and different points between sarcopenia and frailty in chronic liver damage (CLD). Patients and Methods: Patients with both grip strength decline and skeletal muscle index decline were regarded as sarcopenia. Frailty was defined as a syndrome in which 3 or more of the following criteria were met: i) exhaustion, ii) body weight loss, iii) slow walking speed, iv) muscle weakness, and v) low physical activity. Results: Sarcopenia and frailty were identified in 52 patients (15.2\%) and $46(13.5 \%)$, respectively. The prevalence of sarcopenia and frailty was well stratified according to age and the liver cirrhosis (LC) status. In the multivariate analysis, we identified significant factors for sarcopenia: i) age, ii) LC, iii) body mass index and iv) extracellular water (ECW) to total body water $(T B W)$ ratio, while only the ECW to TBW ratio was significant for frailty. Conclusion: Sarcopenia and frailty in CLD should be separately evaluated.
\end{abstract}

In individuals with chronic liver damage (CLD), metabolic functions are frequently damaged leading to several nutritional disorders, including protein-energy-malnutrition, or muscle abnormalities (1). Since sarcopenia, as assessed by

This article is freely accessible online.

*These Authors contributed equally to this study.

Correspondence to: Hiroki Nishikawa, Department of Internal Medicine, Hyogo College of Medicine, 1-1 Mukogawacho, Nishinomiya, Hyogo, 663-8501, Japan. Tel: +81 798456111, Fax: +81 798456608, e-mail: nishikawa_6392_0207@yahoo.co.jp

Key Words: Sarcopenia, frailty, chronic liver damage, common point, different point. muscle mass decrease and muscle strength impairment in patients with CLD, can be related to falls, poor quality of life or poor prognosis, it has become a very interesting topic to examine for physicians (2-8). Sarcopenia is one of the most common consequences found in patients with liver cirrhosis (LC), affecting $30 \%$ to $70 \%$ of LC patients, and it can be a main determinant for the incidence of hepatic encephalopathy in LC patients $(1,9,10-13)$. Japanese CLD patients can now be found in aging populations, and this fact is also a crucial public health issue since aging itself can cause sarcopenia (14-16). To avoid unfavorable consequences related to sarcopenia one needs to assess this disease as a condition with a systemic involvement (17-19). Improving physical activity or nutrition and adequately managing any underlying diseases are essential steps for avoiding sarcopenia (6).

Frailty is a concept globally used in geriatrics that precedes disability, and is defined as a condition of increased vulnerability associated with physiological decline (20-22). Originally, it was proposed to identify elderly people at an elevated risk of adverse health outcomes, dependencies, falls, disabilities, and mortality (20-22). Frailty is determined based on the evaluation of physical, functional and cognitive abilities. The frailty phenotype is defined as the presence of 3 or more of the following criteria: i) body weight (BW) loss, ii) self-reported exhaustion, iii) skeletal muscle function decline, iv) slow walking speed (WS) and v) low physical activity $(23,24)$. Sarcopenia is an important component of frailty (22). Aging is indeed closely linked to changes in body composition, especially skeletal muscle mass decline, resulting in disability and mortality $(14,16,24)$. While any chronic organ dysfunction can also lead to physiological vulnerability (25-27). CLDs are not the exception. Carey, et al. have reported that a six-minute walk reflecting physical function shows a good prediction of mortality for liver 
transplant candidates (25). It was this study that raised an awareness for frailty in patients with CLDs.

The strong overlap between sarcopenia and frailty that can be seen in CLD leads to a condition termed physical frailty $(19,25)$. To translate the clinical relevance of sarcopenia and frailty into practice, borders and bridges between the two should be clearly defined. The aims of the study were to identify the common and different points between sarcopenia and frailty in patients with CLD.

\section{Patients and Methods}

Patients. Three hundred and forty-one CLD patients subjected to evaluation for both sarcopenia and frailty consulted our hospital between July 2015 and October 2019. LC was determined by: i) liver biopsy analysis, ii) radiological findings (deformation of the liver surface, varices or splenomegaly, etc.), iii) liver fibrosis markers, and iv) laboratory data (lower platelet count or prolonged prothrombin time, etc.) (28-31).

Grip strength (GS) was measured according to the current guidelines, and decreased GS was defined as $<26 \mathrm{~kg}$ for men and $<18 \mathrm{~kg}$ for women (14). The skeletal muscle index (SMI) was tested using bioimpedance analysis (BIA) as described previously (32). SMI decline was defined as $<7.0 \mathrm{~kg} / \mathrm{m}^{2}$ in men and $<5.7 \mathrm{~kg} / \mathrm{m}^{2}$ in women referring to the guidelines (14). Patients with both GS decline and SMI decline were regarded as having sarcopenia (14). In all analyzed subjects, the six-meter walking test was done. The test was performed twice in each subject and the walking speed (WS; $\mathrm{m} / \mathrm{s}$ ) was defined as the mean value of the two measured speeds.

Frailty was defined as a clinical syndrome in which 3 or more of the following criteria were met: i) unintentional BW loss ( 2 or $3 \mathrm{~kg}$ or more within the past 6 months), ii) self-reported exhaustion, iii) muscle weakness ( $\mathrm{GS}<26 \mathrm{~kg}$ in men and $<18 \mathrm{~kg}$ in women), iv) slow WS $(<1.0 \mathrm{~m} / \mathrm{s})$, and v) low physical activity (doing light exercise or not), while pre-frailty was defined as patients with one or two of the aforementioned phenotypes. Patients with none of the 5 phenotypes were regarded as having a robust status $(23,24)$.

Due to the intrinsic limitations of BIA, such as the presence of ascites (14), patients with severe ascites were not included in this study. We compared the impact of sarcopenia and frailty in CLD patients in a retrospective manner. Factors associated with sarcopenia or frailty were identified in both univariate and multivariate analysis. In addition, we classified the study cohort into four groups: i) patients with sarcopenia alone (type A), ii) patients with frailty alone (type B), iii) patients with both sarcopenia and frailty (type C) and iv) patients with neither sarcopenia or frailty (type D). Baseline characteristics were compared among the four types.

The institutional review board in our hospital acknowledged this research protocol, and the 1975 Declaration of Helsinki was strictly adhered to ensure the rights of the patients. Due to the retrospective nature of this study, an opt out approach was employed in order to obtain informed consent from the subjects.

Statistics. The JMP 14 software (SAS Institute Inc., Cary, NC) was used for our statistical analyses. For the numerical variables, MannWhitney $U$-test, Student's $t$-test, analysis of variance or Kruskal-
Table I. Baseline characteristics $(n=341)$.

\begin{tabular}{lc}
\hline Variables & All cases $(\mathrm{n}=341)$ \\
\hline Age (years) & $66(55,72)$ \\
Gender, male/female & $164 / 177$ \\
Liver disease etiology & \\
HCV/HBV/HBV and HCV/NBNC & $174 / 61 / 7 / 99$ \\
Presence of sarcopenia, yes/no & $52 / 289$ \\
Presence of frailty, yes/no & $46 / 295$ \\
Presence of LC, yes/no & $122 / 219$ \\
Body mass index $\left(\mathrm{kg} / \mathrm{m}^{2}\right)$ & $22.7(20.5,25.65)$ \\
SMI $\left(\mathrm{kg} / \mathrm{m}^{2}\right)$, male & $7.42(6.83,7.93)$ \\
SMI $\left(\mathrm{kg} / \mathrm{m}^{2}\right)$, female & $5.91(5.42,6.45)$ \\
Walking speed $(\mathrm{m} / \mathrm{s})$ & $1.303(1.1005,1.4445)$ \\
Grip strength $(\mathrm{kg}), \mathrm{male}$ & $33.3(27.925,38.925)$ \\
Grip strength $(\mathrm{kg})$, female & $20.8(17.6,24.45)$ \\
ECW to TBW ratio & $0.390(0.384,0.396)$ \\
Total bilirubin $(\mathrm{mg} / \mathrm{dl})$ & $0.8(0.6,1.1)$ \\
Serum albumin $(\mathrm{g} / \mathrm{dl})$ & $4.3(4.0,4.5)$ \\
ALBI score & $-2.9(-3.12,-2.6)$ \\
ALBI grade, $1 / 2 / 3$ & $256 / 78 / 7$ \\
Prothrombin time $(\%)$ & $91.2(80.55,99.05)$ \\
Platelet count $\left(\times 10^{4} / \mathrm{mm}^{3}\right)$ & $17.5(12.6,22.0)$ \\
AST $(\mathrm{IU} / \mathrm{l})$ & $25(19,34)$ \\
ALT $(\mathrm{IU} / \mathrm{l})$ & $19(14,33)$ \\
ALP $(\mathrm{IU} / \mathrm{l})$ & $243(194,308.5)$ \\
GGT $(\mathrm{IU} / \mathrm{l})$ & $26(17,46)$ \\
Total cholesterol $(\mathrm{mg} / \mathrm{dl})$ & $181(151.25,213)$ \\
Triglyceride $(\mathrm{mg} / \mathrm{dl})$ & $88(67,124)$ \\
HbA1c $(\mathrm{NGSP})$ & $5.7(5.4,6.1)$ \\
eGFR (ml/min/1.73m $\left.{ }^{2}\right)$ & $81(68,93)$ \\
Serum sodium $(\mathrm{mmol} / \mathrm{l})$ & $140(139,141)$ \\
Branched-chain amino acid to tyrosine ratio & $5.645(4.2125,6.795)$ \\
& \\
& \\
&
\end{tabular}

Data are expressed as number or median value (interquartile range). HbAlc: Glycated haemoglobin; HCV: hepatitis C virus; HBV: hepatitis B virus; NBNC: non-B and non-C; LC: liver cirrhosis; SMI: skeletal muscle index; ECW: extracellular water; TBW: total body water; ALBI: albuminbilirubin; AST: aspartate aminotransferase: ALT: alanine aminotransferase; ALP: alkaline phosphatase; GGT: $\gamma$-glutamyltranspeptidase; NGSP: National Glycohemoglobin Standardization Program; eGFR: estimated glomerular filtration rate.

Wallis tests were used to adequately assess group characteristics. For the categorical variables, Fisher's exact test or Pearson $\chi^{2}$ test was used to assess group characteristics. Baseline significant items in our univariate analysis were subjected to the multivariate logistic regression analysis to select candidate parameters. Data were demonstrated as median values [interquartile range (IQR)]. The statistically significant level was set at $p<0.05$.

\section{Results}

Baseline features. Baseline features of the study cohort $(\mathrm{n}=341)$ are presented in Table I. The study cohort included 164 males and 177 females with the median age (IQR) of 66 $(55,72)$ years. LC was identified at baseline in 122 cases $(35.8 \%)$. There were 256 patients $(75.1 \%)$ with albumin- 

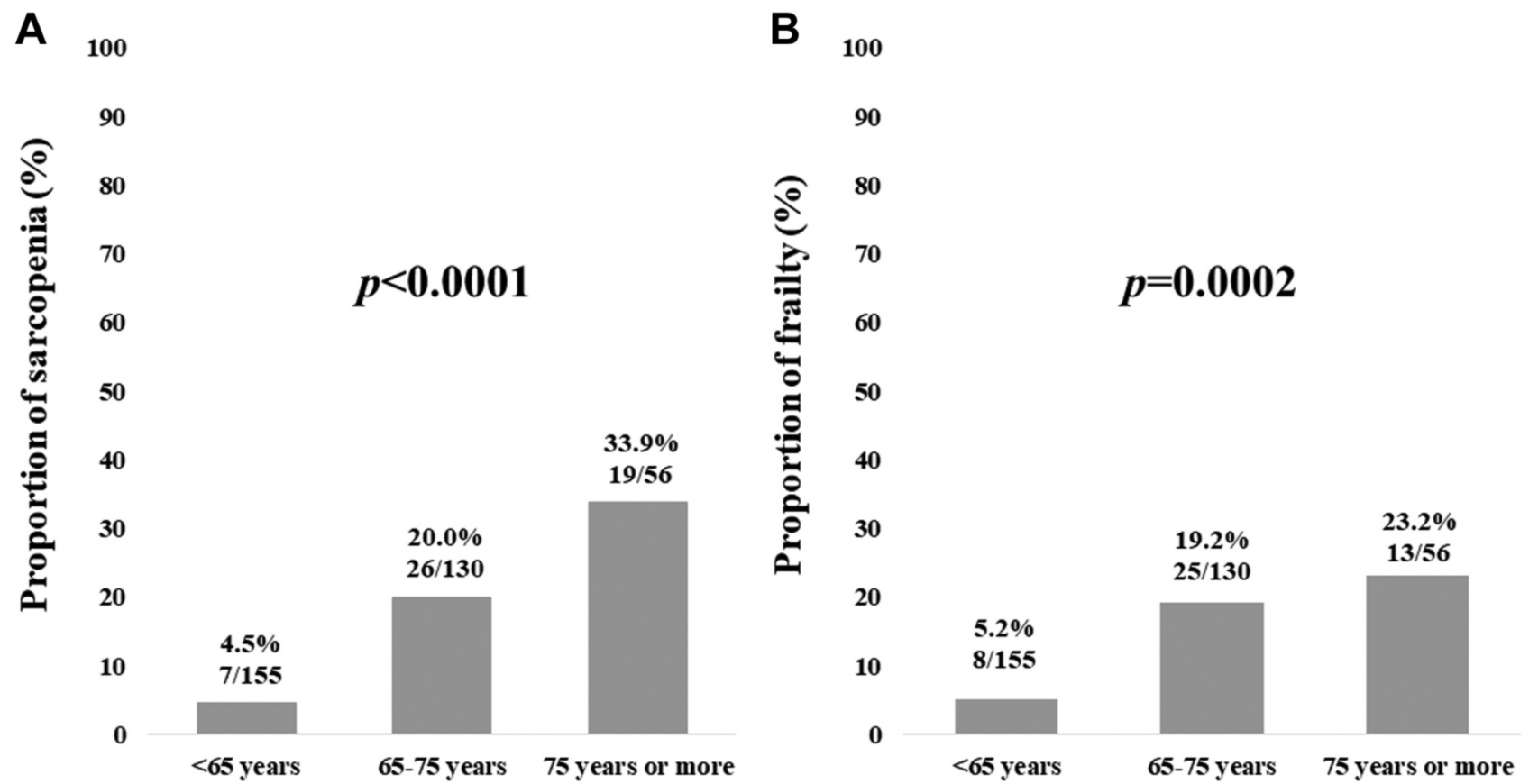

Figure 1. Prevalence of sarcopenia and frailty according to age. (A) Shows prevalence of sarcopenia in patients $<65$ years, 65-75 years and $\geq 75$ years. (B) Prevalence of frailty in patients $<65$ years, $65-75$ years and $\geq 75$ years.

bilirubin (ALBI) grade 1, 78 (22.9\%) with ALBI grade 2 and $7(2.1 \%)$ with ALBI grade 3 (33).

In men, the median (IQR) GS was $33.3 \mathrm{~kg}$ (27.925, $38.925 \mathrm{~kg}$ ), while in women, the median (IQR) GS was 20.8 $\mathrm{kg}(17.6,24.45 \mathrm{~kg})$. Thirty-two men $(19.5 \%)$ and 48 women (27.1\%) had decreased GS. In men, the median (IQR) SMI was $7.42 \mathrm{~kg} / \mathrm{m}^{2}\left(6.83,7.93 \mathrm{~kg} / \mathrm{m}^{2}\right)$, while in female, the median (IQR) SMI was $5.91 \mathrm{~kg} / \mathrm{m}^{2}\left(5.42,6.45 \mathrm{~kg} / \mathrm{m}^{2}\right)$. Fiftythree men $(32.3 \%)$ and 65 women $(36.7 \%)$ had decreased SMI. Sarcopenia was identified in 52 patients (15.2\%).

The median (IQR) WS was $1.30 \mathrm{~m} / \mathrm{s}(1.10,1.44 \mathrm{~m} / \mathrm{s})$. Fifty-one patients $(15.0 \%)$ had decreased WS. One hundred and sixty-eight patients $(49.3 \%)$ reported exhaustion. Fifteen patients $(4.4 \%)$ reported BW loss. Ninety patients $(26.4 \%)$ reported low physical activity. Frailty score ranged from 0 to 5 (median value=1). Robust (frailty score 0 ), pre-frail (score 1 or 2) and frail (frailty score 3 or more) were identified in 108 (31.7\%), 187 (54.8\%) and 46 (13.5\%) CLD patients, respectively.

Prevalence of sarcopenia or frailty according to age. Prevalence of sarcopenia in patients $<65$ years, 65-75 years and $\geq 75$ years were $4.5 \%(7 / 155), 20.0 \%(26 / 130)$ and $33.9 \%(19 / 56)$, respectively $(p<0.0001)$ (Figure 1A). Prevalence of frailty in patients $<65$ years, $65-75$ years and $\geq 75$ years were $5.2 \%(8 / 155), 19.2 \%(25 / 130)$ and $23.2 \%$ $(13 / 56)$, respectively $(p=0.0002)$ (Figure 1B). Prevalence of pre-frailty or frailty in patients $<65$ years, $65-75$ years and $\geq 75$ years were $56.8 \%(88 / 155), 73.1 \%(95 / 130)$ and $89.3 \%$ $(50 / 56)$, respectively $(p<0.0001)$.

Prevalence of sarcopenia or frailty according to body mass index. Prevalence of sarcopenia in patients with body mass index (BMI) $<20 \mathrm{~kg} / \mathrm{m}^{2},>20 \mathrm{~kg} / \mathrm{m}^{2},<25 \mathrm{~kg} / \mathrm{m}^{2}$ and $\geq 25$ $\mathrm{kg} / \mathrm{m}^{2}$ were $25.8 \%(16 / 62), 20.0 \%(35 / 175)$, and $1.0 \%$ $(1 / 104)$, respectively $(p<0.0001)$ (Figure 2A). Prevalence of frailty in patients with BMI $<20 \mathrm{~kg} / \mathrm{m}^{2},>20 \mathrm{~kg} / \mathrm{m}^{2},<25$ $\mathrm{kg} / \mathrm{m}^{2}$ and $\geq 25 \mathrm{~kg} / \mathrm{m}^{2}$ were $17.7 \%$ (11/62), $12.0 \%$ (21/175), and $13.5 \%(14 / 104)$, respectively $(p=0.5237)$ (Figure $2 \mathrm{~B})$.

Proportion of LC in patients with sarcopenia and nonsarcopenia, and in patients with frailty and non-frailty. The proportion of LC in sarcopenic patients was significantly higher compared to non-sarcopenic patients [55.8\% (29/52) vs. 32.2\% (93/289), $p=0.0016$ ] (Figure 3A). The proportion of LC in patients with frailty was significantly higher compared to patients with non-frailty [67.4\% (31/46) vs. $30.9 \%(91 / 295), p<0.0001]$ (Figure 3B).

Proportion of WS decrease, fatigue, BW loss and low physical activity in patients with sarcopenia or nonsarcopenia. The proportion of WS decrease in patients with sarcopenia was significantly higher compared to patients with non-sarcopenia $[36.5 \%(19 / 52)$ vs. $11.1 \%$ (32/289), 


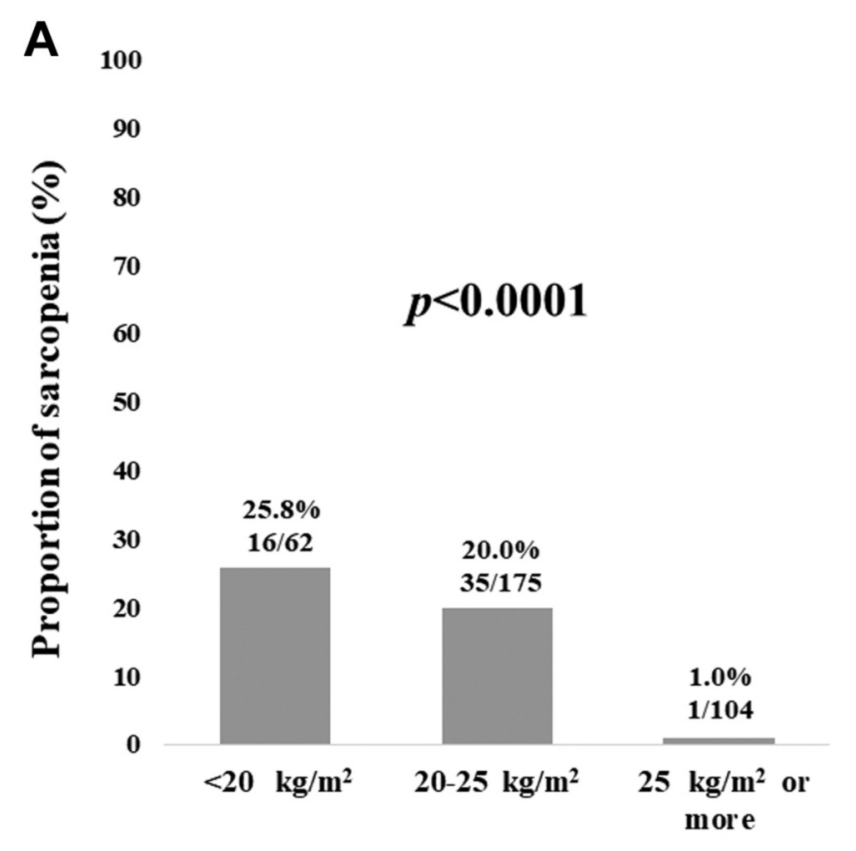

Body mass index

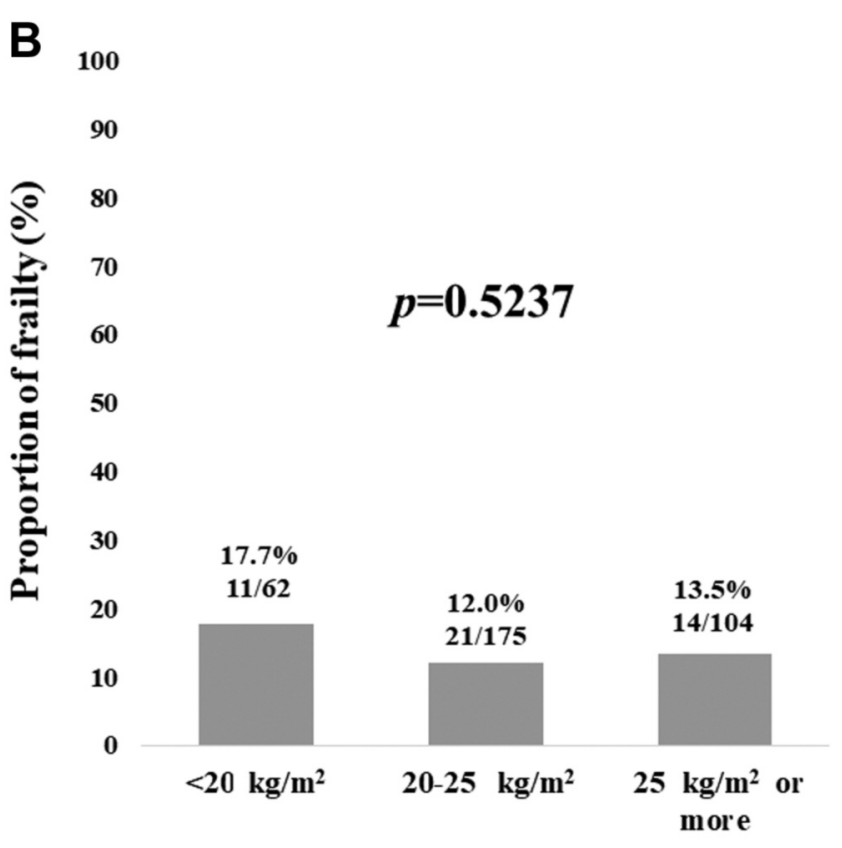

Body mass index

Figure 2. Prevalence of sarcopenia and frailty according to body mass index. (A) Prevalence of sarcopenia in patients with body mass index $(B M I)<20 \mathrm{~kg} / \mathrm{m}^{2},>20 \mathrm{~kg} / \mathrm{m}^{2},<25 \mathrm{~kg} / \mathrm{m}^{2}$ and $\geq 25 \mathrm{~kg} / \mathrm{m}^{2}$. (B) Prevalence of frailty in patients with $\mathrm{BMI}<20 \mathrm{~kg} / \mathrm{m}^{2},>20 \mathrm{~kg} / \mathrm{m}^{2},<25 \mathrm{~kg} / \mathrm{m}^{2} \mathrm{and} \geq 25 \mathrm{~kg} / \mathrm{m}^{2}$.

$p<0.0001$ ], while no significant link was observed in patients presenting with fatigue and BW loss [fatigue: $55.8 \%(29 / 52)$ vs. $48.1 \%$ (139/289), $p=0.3665$; and BW loss: $5.8 \%(3 / 52)$ vs. $4.2 \%$ (12/289), $p=0.7104]$ (Figures 4A-C). The proportion of low physical activity in patients with sarcopenia was higher with a tendency for significance compared to patients with non-sarcopenia [36.5\% (19/52) vs. 24.6\% (71/289), $p=0.0870$ ] (Figure 4D).

Uni- and multivariate analyses of factors related to the presence of sarcopenia. In the univariate analysis, i) age $(p=0.0458)$, ii) presence of LC $(p=0.0016)$, iii) serum albumin level $(p=0.0017)$, iv) BMI $(p<0.0001)$, v) ALBI score $(p=0.0357)$, and vi) extracellular water (ECW) to total body water (TBW) ratio $(p<0.0001)$ were significant factors associated with the presence of sarcopenia (Table II). The ALBI score includes total bilirubin and serum albumin; thus, the serum albumin level was not included in the multivariate analysis. In the multivariate analysis for the remaining 5 factors, i) advanced age $(p=0.0114)$, ii) presence of LC $(p=0.0227)$, iii) lower BMI $(p<0.0001)$ and iv) higher ECW to TBW ratio $(p=0.0002)$ were identified as significant for the presence of sarcopenia (Table III).

Uni- and multivariate analyses of factors related to the presence of frailty. In the univariate analysis, i) age $(p=0.0002)$, ii) presence of LC $(<0.0001)$, iii) serum albumin level $(p<0.0001)$, iv) ALBI score $(p<0.0001)$, v) alkaline phosphatase (ALP) $(p=0.0065)$, vi) branched-chain amino acid to tyrosine ratio (BTR) $(p=0.0083)$ and vii) $\mathrm{ECW}$ to TBW ratio $(p<0.0001)$ were significant factors associated with the presence of frailty (Table IV). Serum albumin level was not included in the multivariate analysis due to the same reason as mentioned above. In the multivariate analysis for the remaining 6 factors, only a higher $\mathrm{ECW}$ to $\mathrm{TBW}$ ratio $(p<0.0001)$ was found to be significantly linked to the presence of frailty (Table V).

Comparison of baseline characteristics among the four groups (type $A, B, C$ and $D$ ). There were 32 patients (9.4\%) with type A, 26 (7.6\%) with type B, 20 (5.9\%) with type C and $263(77.1 \%)$ with type D. Comparing baseline characteristics among the four groups, overall significance was noted in terms of: i) age $(p<0.0001)$ (Figure 5A), ii) BMI $(p<0.0001)$ (Figure $5 \mathrm{~B})$, iii) $\mathrm{ECW}$ to $\mathrm{TBW}$ ratio $(p<0.0001)$ (Figure 5C), iv) serum albumin level $(p<0.0001)$ (Figure 5D), v) ALBI score ( $p=0.0002)$ (Figure 5E), vi) ALP $(p=0.0017)$ (Figure 5F), vii) BTR $(p=0.0015$, Figure $5 \mathrm{G})$, and viii) proportion of LC $(p<0.0001)$ (Figure 6). The prevalence of LC in each type was: i) $53.1 \%$ (17/32) in type A, ii) $73.1 \%(19 / 26)$ in type B, iii) $60.0 \%(12 / 20)$ in type C, and iv) $28.1 \%(74 / 263)$ in type D. The $p$-Values from the 
A

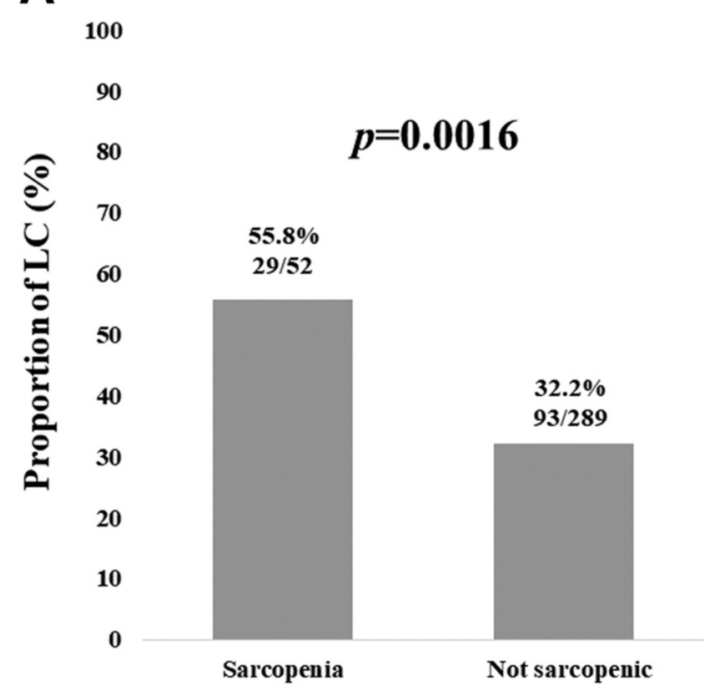

B

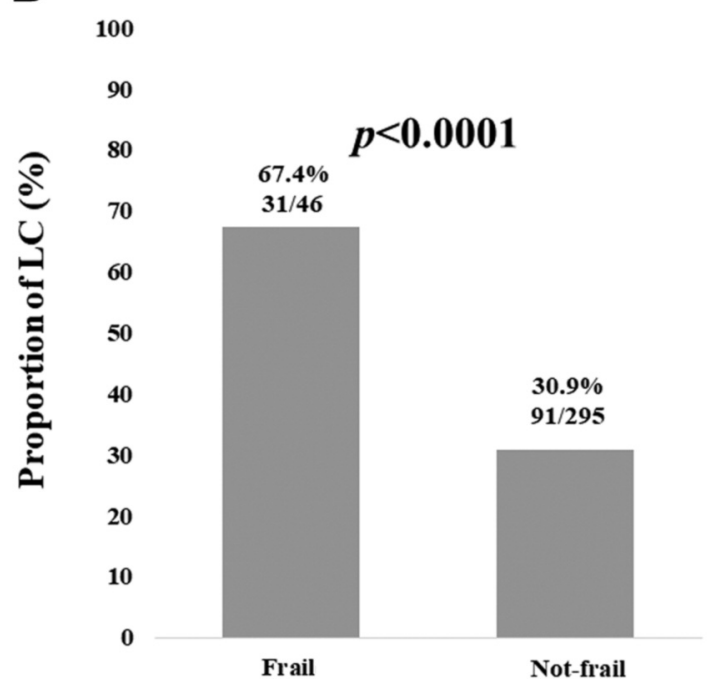

Figure 3. Liver cirrhosis in sarcopenic and frail patients. (A) Proportion of liver cirrhosis (LC) in sarcopenic and non-sarcopenic patients. (B) Proportion of LC in patients with frailty and no frailty.

A

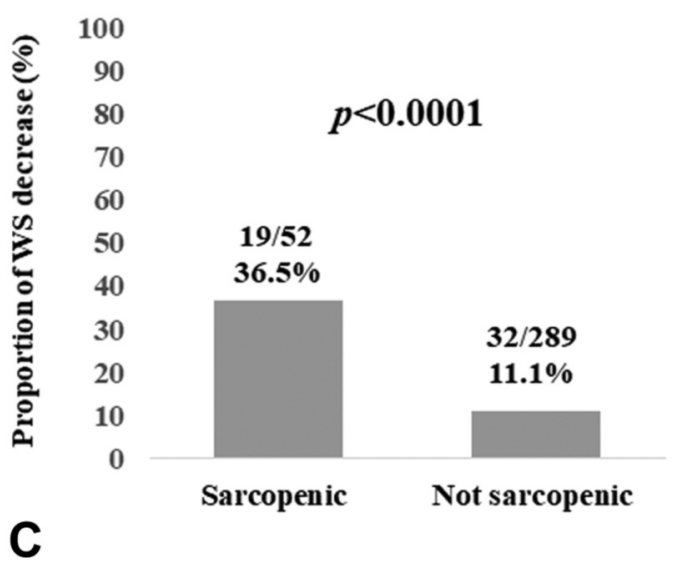

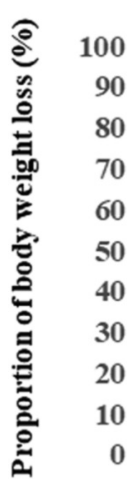

$p=0.7104$

$\mathbf{3} / \mathbf{5 2}$

$\mathbf{5 . 8} \%$

Sarcopenic
$12 / 289$

$4.2 \%$

\section{Not sarcopenic}

B

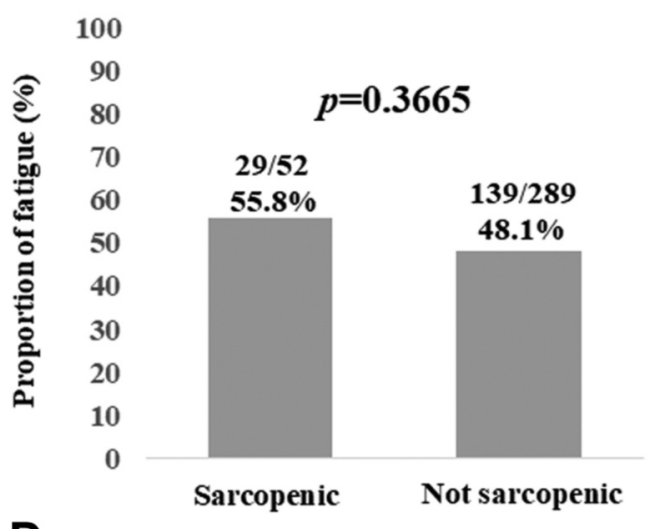

D

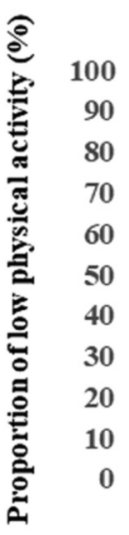

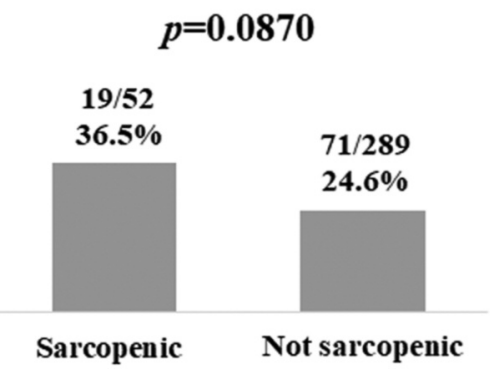

Figure 4. Characteristics of patients with sarcopenia. (A) Proportion of walking speed decrease $(<1.0 \mathrm{~m} / \mathrm{s}),(B)$ fatigue, (C) body weight loss, and (D) low physical activity. 
Table II. Univariate analyses of factors linked to the presence of sarcopenia.

\begin{tabular}{|c|c|c|c|}
\hline Variables & $\begin{array}{l}\text { Sarcopenia } \\
\quad(\mathrm{n}=52)\end{array}$ & $\begin{array}{l}\text { Non-sarcopenia } \\
\quad(\mathrm{n}=289)\end{array}$ & $p$-Value \\
\hline Age (years) & $73(67,77)$ & $64(53,71)$ & 0.0458 \\
\hline $\begin{array}{l}\text { Gender, } \\
\text { male/female }\end{array}$ & $21 / 31$ & $143 / 146$ & 0.4540 \\
\hline $\begin{array}{l}\mathrm{HCV} / \mathrm{HBV} / \mathrm{HBV} \\
\text { and } \mathrm{HCV} / \mathrm{NBNC}\end{array}$ & $28 / 5 / 1 / 18$ & $146 / 56 / 6 / 81$ & 0.3754 \\
\hline $\begin{array}{l}\text { Body mass index } \\
\left(\mathrm{kg} / \mathrm{m}^{2}\right)\end{array}$ & $20.7(19.8,21.9)$ & $23.5(21,26)$ & $<0.0001$ \\
\hline $\begin{array}{l}\text { Presence of LC, } \\
\text { yes/no }\end{array}$ & $29 / 23$ & $93 / 196$ & 0.0016 \\
\hline $\begin{array}{l}\text { Total bilirubin } \\
(\mathrm{mg} / \mathrm{dl})\end{array}$ & $0.7(0.525,1.0)$ & $0.9(0.7,1.1)$ & 0.0511 \\
\hline $\begin{array}{l}\text { Serum albumin } \\
(\mathrm{g} / \mathrm{dl})\end{array}$ & $4.1(3.725,4.4)$ & $4.3(4.0,4.6)$ & 0.0017 \\
\hline ALBI score & $-2.76(-2.99,-2.48)$ & $-2.91(-3.14,-2.62)$ & 0.0357 \\
\hline $\begin{array}{l}\text { Prothrombin } \\
\text { time }(\%)\end{array}$ & $90.25(78.65,99.8)$ & $91.4(81.0,98.7)$ & 0.9335 \\
\hline $\begin{array}{l}\text { Platelet count } \\
\left(\times 10^{4} / \mathrm{mm}^{3}\right)\end{array}$ & $16.15(12.125,18.85)$ & $17.6(12.9,22.5)$ & 0.4341 \\
\hline AST (IU/l) & $25(20.25,40.75)$ & $25(19,33)$ & 0.8094 \\
\hline ALT (IU/l) & $17(13,32)$ & $20(14,33)$ & 0.2578 \\
\hline ALP (IU/l) & $275(213.5,368.5)$ & $236(193,302)$ & 0.4741 \\
\hline GGT (IU/l) & $24(16,41.75)$ & $26(17,47)$ & 0.6026 \\
\hline $\begin{array}{l}\text { Total cholesterol } \\
(\mathrm{mg} / \mathrm{dl})\end{array}$ & $180.5(140.5,217.75)$ & $181(155.25,213)$ & 0.1867 \\
\hline $\begin{array}{l}\text { Triglyceride } \\
(\mathrm{mg} / \mathrm{dl})\end{array}$ & $92.5(68.25,116.5)$ & $88(67,125.75)$ & 0.9087 \\
\hline $\begin{array}{l}\text { eGFR } \\
\left(\mathrm{ml} / \mathrm{min} / 1.73 \mathrm{~m}^{2}\right)\end{array}$ & $77.5(62.75,95.75)$ & $81(68.5,92.5)$ & 0.1721 \\
\hline $\mathrm{HbA1c}$ (NGSP) & $5.7(5.4,6.075)$ & $5.7(5.4,6.1)$ & 0.2908 \\
\hline $\begin{array}{l}\text { Serum sodium } \\
(\mathrm{mmol} / \mathrm{l})\end{array}$ & $140(138.25,142)$ & $140(139,141)$ & 0.5353 \\
\hline BTR & $5.23(3.9275,6.905)$ & $5.72(4.36,6.765)$ & 0.5011 \\
\hline $\begin{array}{l}\mathrm{ECW} \text { to } \mathrm{TBW} \\
\text { ratio }\end{array}$ & $0.3975(0.392,0.403)$ & $0.388(0.383,0.394)$ & $<0.0001$ \\
\hline
\end{tabular}

Data are expressed as number or median value (interquartile range). HbA1c: Glycated haemoglobin; HCV: hepatitis C virus; HBV: hepatitis B virus; NBNC: non-B and non-C; LC: liver cirrhosis; ALBI: albuminbilirubin; AST: aspartate aminotransferase; ALT: alanine aminotransferase; ALP: alkaline phosphatase; GGT: $\gamma$-glutamyltranspeptidase; eGFR: estimated glomerular filtration rate; NGSP: National Glycohemoglobin Standardization Program; BTR: branched-chain amino acid to tyrosine ratio; ECW: extracellular water; TBW: total body water.

comparisons (numerical parameters) between each two types are listed in Table VI.

\section{Discussion}

Recently, the concept of frailty has been assigned to CLDs as part of clinical symptoms concerning impaired global physical function $(25,34-39)$. It has not yet been clearly delineated whether sarcopenia and frailty in CLDs are

Table III. Multivariate analysis of factors associated with sarcopenia.

\begin{tabular}{lccr}
\hline Sarcopenia & HR & $95 \%$ CI & $p$-Value \\
\hline Age (per one year) & 1.047 & $1.009-1.088$ & 0.0114 \\
ALBI score (per one) & 2.205 & $0.959-5.072$ & 0.0567 \\
BMI (per one kg/m ${ }^{2}$ ) & 0.736 & $0.652-0.830$ & $<0.0001$ \\
ECW to TBW ratio (per one) & $2.55 \mathrm{e}+40$ & $8.43 \mathrm{e}+18-7.71 \mathrm{e}+61$ & 0.0002 \\
Presence of LC & 2.532 & $1.140-5.624$ & 0.0225 \\
\hline
\end{tabular}

HR: Hazard ratio; CI: confidence interval; ALBI: albumin-bilirubin; BMI: body mass index; ECW: extracellular water; TBW: total body water; LC: liver cirrhosis.

Table IV. Univariate analyses of factors linked to the presence of frailty.

\begin{tabular}{|c|c|c|c|}
\hline Variables & $\begin{array}{l}\text { Frailty } \\
(n=46)\end{array}$ & $\begin{array}{l}\text { Non-frailty } \\
\quad(n=295)\end{array}$ & $p$-Value \\
\hline Age (years) & $73(68,75.25)$ & $65(54,71)$ & 0.0002 \\
\hline Gender, male/female & $20 / 26$ & $144 / 151$ & 0.7836 \\
\hline $\begin{array}{l}\mathrm{HCV} / \mathrm{HBV} / \mathrm{HBV} \\
\text { and } \mathrm{HCV} / \mathrm{NBNC}\end{array}$ & $20 / 5 / 1 / 20$ & $154 / 56 / 6 / 79$ & 0.1174 \\
\hline $\begin{array}{l}\text { Body mass index } \\
\left(\mathrm{kg} / \mathrm{m}^{2}\right)\end{array}$ & $21.55(19.975,25.5)$ & $22.8(20.8,25.7)$ & 0.3701 \\
\hline $\begin{array}{l}\text { Presence of LC, } \\
\text { yes/no }\end{array}$ & $31 / 15$ & $91 / 204$ & $<0.0001$ \\
\hline $\begin{array}{l}\text { Total bilirubin } \\
(\mathrm{mg} / \mathrm{dl})\end{array}$ & $0.8(0.6,1.35)$ & $0.8(0.6,1.1)$ & 0.9042 \\
\hline Serum albumin & $4.0(3.075,4.3)$ & $4.3(4.0,4.6)$ & $<0.0001$ \\
\hline
\end{tabular}

Serum

$(\mathrm{g} / \mathrm{dl})$

ALBI score $\quad-2.65(-2.9425,-1.715)-2.93(-3.15,-2.67)<0.0001$

$\begin{array}{llll}\text { Prothrombin } & 87.05(71.175,100.425) & 91.4(81.3,98.7) & 0.2037\end{array}$

time (\%)

$\begin{array}{llll}\text { Platelet count } & 14.7(9.35,19.15) & 17.9(13.0,22.2) & 0.0543\end{array}$

$\left(\times 10^{4} / \mathrm{mm}^{3}\right)$

AST (IU/)

ALT (IU/l)

ALP (IU/l)

GGT (IU/l)

Total cholesterol

$$
28(21,43)
$$

$21(13.75,36.25)$

$276(213.5,414)$

$27(15,49.75)$

$163(141.5,204.5)$

$(\mathrm{mg} / \mathrm{dl})$

Triglyceride

$(\mathrm{mg} / \mathrm{dl})$

eGFR

$\left(\mathrm{ml} / \mathrm{min} / 1.73 \mathrm{~m}^{2}\right)$

HbA1c (NGSP)

Serum sodium

$(\mathrm{mmol} / \mathrm{l})$

BTR

ECW to TBW

$83.5(68.75,106.25)$

$81(64.5,91.75)$

$5.85(5.375,6.525)$

$139.5(138,142)$

$25(19,33)$

0.0992

$236(193,300)-0.6717$

$26(17,46) \quad 0.8044$

$183.5(156.75,215) \quad 0.0815$

ratio

Data are expressed as number or median value (interquartile range) HbA1c: Glycated haemoglobin; HCV: hepatitis C virus; HBV: hepatitis B virus; NBNC: non-B and non-C; LC: liver cirrhosis; ALBI: albuminbilirubin; AST: aspartate aminotransferase; ALT: alanine aminotransferase; ALP: alkaline phosphatase; GGT: $\gamma$-glutamyltranspeptidase; eGFR: estimated glomerular filtration rate; NGSP: National Glycohemoglobin Standardization Program; BTR: branched-chain amino acid to tyrosine ratio; ECW: extracellular water; TBW: total body water. 
A

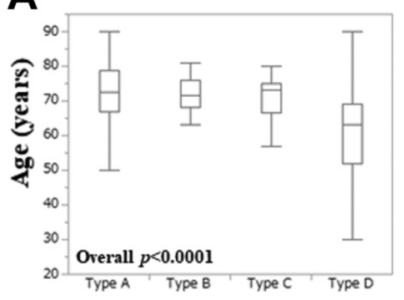

B

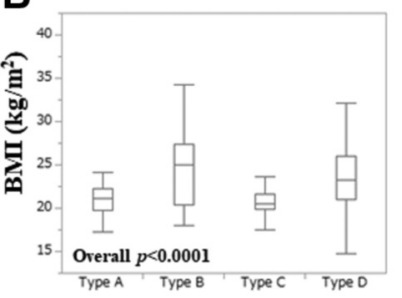

$\mathbf{F}$
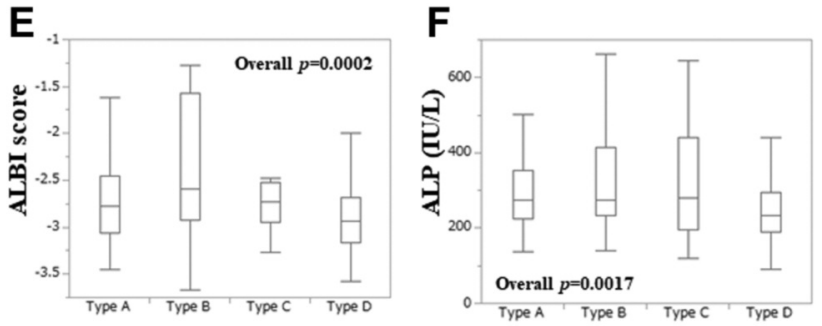

C

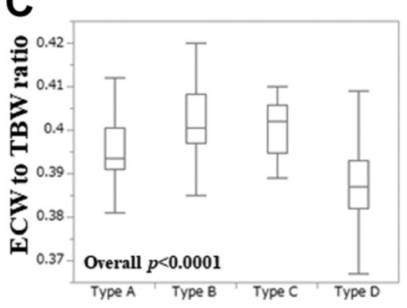

G
D

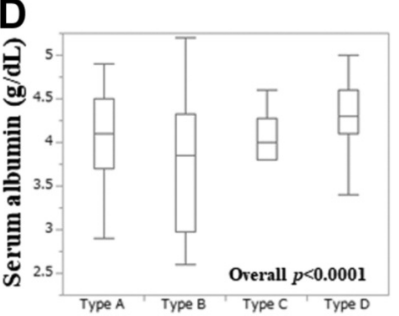

Type A, $n=32(9.4 \%)$

Type B, $n=26(7.6 \%)$

Type C, $n=20(5.9 \%)$

Type D, $n=263(77.1 \%)$

Figure 5. Comparison of baseline characteristics (numerical parameters) among four types (type A, B, $C$ and D). (A) age, (B) body mass index (BMI), (C) extracellular water (ECW) to total body water (TBW) ratio, (D) serum albumin level, (E) albumin-bilirubin (ALBI) score, (F) alkaline phosphatase $(A L P)$, and $(G)$ branched-chain amino acid to tyrosine ratio (BTR). Type A indicates patients with sarcopenia alone. Type B indicates patients with frailty alone. Type $C$ indicates patients with both sarcopenia and frailty. Type $D$ indicates patients with neither sarcopenia or frailty.

Table V. Multivariate analysis of factors associated with frailty.

\begin{tabular}{lccr}
\hline Frailty & HR & 95\%CI & $p$-Value \\
\hline Age (per one year) & 2.667 & $0.184-38.673$ & 0.4710 \\
ALBI score (per one) & 1.003 & $0.355-2.838$ & 0.9949 \\
ECW to TBW ratio (per one) & $8.69 \mathrm{e}+65$ & $3.18 \mathrm{e}+40-2.37 \mathrm{e}+91$ & $<0.0001$ \\
BTR (per one) & 0.876 & $0.651-1.181$ & 0.3862 \\
ALP (per one IU/1) & 1.001 & $0.999-1.004$ & 0.1636 \\
Presence of LC & 2.395 & $0.806-7.117$ & 0.1160
\end{tabular}

HR: Hazard ratio; CI: confidence interval; ALBI: albumin-bilirubin; ECW: extracellular water; TBW: total body water; BTR: branched-chain amino acid to tyrosine ratio; ALP: alkaline phosphatase; LC: liver cirrhosis.

synonyms. Few studies have assessed both sarcopenia and frailty as such in CLDs. Banjhi et al. have reported that in both alcoholic liver disease and non-alcoholic steatohepatitis, there was a large difference between the prevalence of sarcopenia on computed tomography scans and frailty (40). Despite the overlap between definitions and diagnostic criteria, sarcopenia is not identical to frailty. Frailty is a multidimensional clinical entity involving not only the muscle status but also the well-being, disabilities, exhaustion, dependencies and cognitive status. While skeletal muscle mass decline and functional decline can be a strong substratum of frailty (41), the opposite does not always stand true and the absence of sarcopenia certainly does not always deny the presence of frailty. Clues for frailty should lead to

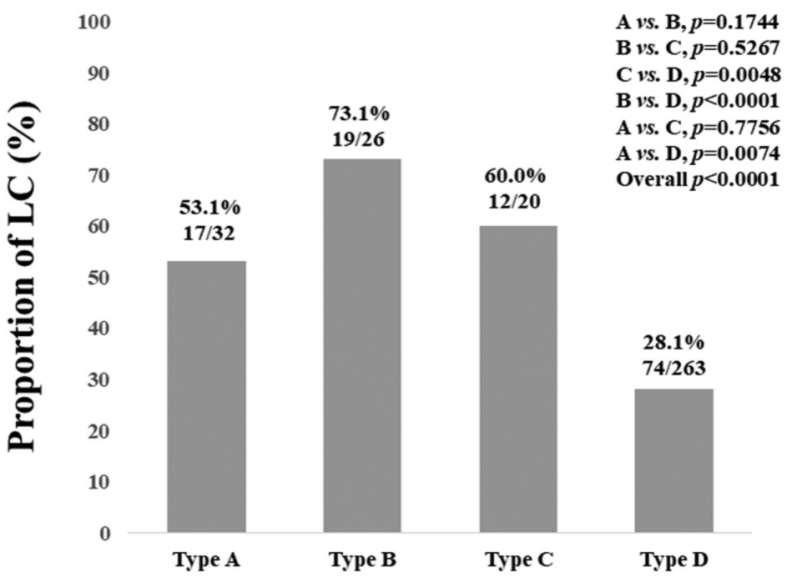

Figure 6. The prevalence of liver cirrhosis among four types (type $A, B$, $C$ and $D$ ). Type $A$ indicates patients with sarcopenia alone. Type $B$ indicates patients with frailty alone. Type $C$ indicates patients with both sarcopenia and frailty. Type $D$ indicates patients with neither sarcopenia or frailty. LC: Liver cirrhosis.

an assessment of body composition. Based on these facts regarding sarcopenia and frailty in CLDs, we believe that common and different points in sarcopenia and frailty for patients with CLDs should be clarified.

In our data, there were 32 patients $(9.4 \%)$ with type A (sarcopenia alone), 26 (7.6\%) with type B (frailty alone), and $20(5.9 \%)$ with type $\mathrm{C}$ (both sarcopenia and frailty). In addition, i) advanced age, ii) presence of LC, iii) a lower BMI 
Table VI. Comparison of baseline characteristics in the four types (Type A, B, C and D).

\begin{tabular}{|c|c|c|c|c|c|c|c|}
\hline & $\begin{array}{l}\text { A } v s . \mathrm{B} \\
p \text {-Value }\end{array}$ & $\begin{array}{l}\mathrm{B} v s . \mathrm{C} \\
p \text {-Value }\end{array}$ & $\begin{array}{l}\text { C vs. A } \\
p \text {-Value }\end{array}$ & $\begin{array}{l}\text { A } v s . \mathrm{D} \\
p \text {-Value }\end{array}$ & $\begin{array}{l}\mathrm{B} v s . \mathrm{D} \\
p \text {-Value }\end{array}$ & $\begin{array}{l}\text { C vs. D } \\
p \text {-Value }\end{array}$ & $\begin{array}{l}\text { Overall } \\
p \text {-Value }\end{array}$ \\
\hline Age & 0.3858 & 0.8853 & 0.3402 & $<0.0001$ & 0.0004 & 0.0031 & $<0.0001$ \\
\hline BMI & 0.0008 & 0.0016 & 0.4814 & $<0.0001$ & 0.2411 & 0.0001 & $<0.0001$ \\
\hline $\mathrm{ECW}$ to $\mathrm{TBW}$ ratio & 0.0134 & 0.7701 & 0.0467 & $<0.0001$ & $<0.0001$ & $<0.0001$ & $<0.0001$ \\
\hline Total bilirubin & 0.0616 & 0.0583 & 0.7187 & 0.0751 & 0.2287 & 0.0593 & 0.0545 \\
\hline Serum albumin & 0.1151 & 0.7223 & 0.3081 & 0.0161 & 0.0002 & 0.0011 & $<0.0001$ \\
\hline ALBI score & 0.0734 & 0.3292 & 0.5724 & 0.0650 & 0.0003 & 0.0193 & 0.0002 \\
\hline Prothrombin time & 0.1648 & 0.1632 & 0.8661 & 0.7066 & 0.0338 & 0.9299 & 0.2077 \\
\hline Platelet count & 0.2690 & 0.2976 & 0.9500 & 0.3740 & 0.0262 & 0.5218 & 0.1345 \\
\hline AST & 0.1132 & 0.8166 & 0.0876 & 0.5055 & 0.1529 & 0.1180 & 0.1706 \\
\hline ALT & 0.2123 & 0.9852 & 0.2558 & 0.1198 & 0.8534 & 0.8877 & 0.4564 \\
\hline ALP & 0.5896 & 0.4714 & 0.7491 & 0.0081 & 0.0029 & 0.1875 & 0.0017 \\
\hline GGT & 0.1569 & 0.5518 & 0.4891 & 0.4791 & 0.2401 & 0.7802 & 0.5454 \\
\hline Total cholesterol & 0.7518 & 0.2060 & 0.1072 & 0.8598 & 0.5708 & 0.0341 & 0.1984 \\
\hline Triglyceride & 0.2473 & 0.6034 & 0.5958 & 0.7788 & 0.2187 & 0.6077 & 0.6125 \\
\hline $\mathrm{HbAlc}$ & 0.8411 & 0.2060 & 0.1325 & 0.9959 & 0.8005 & 0.0655 & 0.3278 \\
\hline eGFR & 0.9377 & 0.5203 & 0.6515 & 0.6152 & 0.9764 & 0.3163 & 0.7674 \\
\hline Serum sodium & 0.4120 & 0.8495 & 0.3181 & 0.7066 & 0.4037 & 0.2664 & 0.5685 \\
\hline BTR & 0.0470 & 0.0101 & 0.4461 & 0.1745 & 0.0002 & 0.8232 & 0.0015 \\
\hline
\end{tabular}

Type A: Patients with sarcopenia alone; Type B: patients with frailty alone; Type C: patients with both sarcopenia and frailty; Type D: patients without both sarcopenia and frailty; BMI: body mass index; ECW: extracellular water; HbA1c: glycated haemoglobin; TBW: total body water; ALBI: albumin-bilirubin; AST: aspartate aminotransferase; ALT: alanine aminotransferase; ALP: alkaline phosphatase; GGT: $\gamma$ glutamyltranspeptidase; eGFR: estimated glomerular filtration rate; BTR: branched-chain amino acid to tyrosine ratio.

and iv) a higher ECW to TBW ratio were independent predictors for sarcopenia, while only a higher ECW to TBW ratio was an independent predictor for frailty. By comparing between type A and type B, significant differences were noted in terms of BMI, ECW to TBW ratio and BTR. These findings raised our awareness that sarcopenia and frailty in CLDs are not synonymous. On the other hand, a significantly high proportion of LC in sarcopenic and frailty patients compared with each counterpart (i.e., not sarcopenic and not frailty patients) implies that underlying liver diseases can be involved not only in sarcopenia but also in frailty, highlighting common points between the two conditions in CLDs. Stratification of the prevalence of sarcopenia or frailty according to age is another common points between the two conditions in CLDs. While sarcopenia was associated with a WS decline and a low physical activity, it was not associated with fatigue or BW loss. Sarcopenia in CLDs is indeed similar to physical frailty (41). Sarcopenia may be the dominant driver of the physical frailty phenotype, especially in LC patients where hepatic synthetic impairment may accelerate the skeletal muscle mass decrease $(14,42,43)$.

In our data, $13.5 \%$ of our patients had frailty, while Fozouni et al. have reported that out of 291 LC patients, 54 LC patients (19\%) had frailty (42). This is probably due to the difference of background patient population (prevalence of LC: $35.8 \%$ in our data vs. $100 \%$ in the study by Fozouni et al.) (42). Age-stratified meta-analyses reported by Kojima et al. have demonstrated that the pooled prevalence of frailty among elderly people living in Japan was 1.9\% (65-69 years), 3.8\% (70-74 years), $10.0 \%$ (75-79 years), $20.4 \%$ (8084 years), and $35.1 \%$ (85 years or more) (44). In our data, the prevalence of frailty in patients $<65$ years, 65-69 years, 70-74 years, $75-79$ years, $80-84$ years and $\geq 85$ years were $5.2 \%$ (8/155), 8.8\% (6/68), 30.7\% (19/62), $27.0 \%$ (10/37), $15.4 \%(2 / 13)$ and $16.7 \%(1 / 6)$, respectively. Especially in our CLD patients aged 70-74 years, the prevalence of frailty was prominently higher compared to similar age elderly people living in Japan, which may be linked to the influence of underlying CLDs on frailty. Notably, a pre-frailty status (frailty score 1 or 2) was identified in $54.8 \%$ of our patients. Clinicians should be aware of the high prevalence of the prefrailty status in CLDs. Early identification of frailty in CLDs can lead to optimization of the CLD patients with the potential for avoiding poor outcomes (45).

Elevated ECW to TBW ratio was an independent factor associated with both the presence of sarcopenia and frailty. ECW to TBW ratio defines the extracellular fluid status (water homeostasis) in the whole body and the liver functional reserve $(46,47)$. Excessive extracellular fluid in CLDs may also lead to the physical functional decline as well as a cognitive decline, which can be linked to our current results (48-50). Excessive extracellular fluid in the brain can cause cognitive decline $(49,50)$. While, notably, the prevalence of sarcopenia was closely linked to BMI, however, frailty was 
not in the multivariate analyses. These results suggest that lower BMI in CLDs involves a poorer muscle status, however, it does not involve phenotypes other than muscle status. Also, in CLDs, higher BMI itself cannot exclude the possibility of frailty although CLD patients with higher BMI have low possibility for sarcopenia. This can be a significant different point between sarcopenia and frailty in CLDs.

Several limitations associated with the study should be mentioned. Firstly, this was a retrospective cross-sectional observational study with patients from a single hospital. Secondly, our data included population data from CLDs patients in Japan, thus, additional studies on patients from other parts of the world are necessary to confirm and expand or adapt our results for each population. Thirdly, patients with large ascites who could suffer from a WS decline were excluded due to the limits of BIA, possibly making this a bias. Finally, due to the cross-sectional nature of our study, the causal relationship between sarcopenia and frailty is unclear. Interpretation with caution to our data is needed. Our study results nevertheless implied that sarcopenia and frailty in CLDs had several common and a few different points. In conclusion, sarcopenia and frailty in CLDs are not synonyms. These two important clinical entities should be separately evaluated.

\section{Conflicts of Interest}

The Authors have no conflicts to declare.

\section{Authors' Contributions}

Data curation: HN, KY, HE, YI, YS, KK, YS, NI, TT, NA, RT, KH, TK, YY, TN and SN. Formal analysis: HN, supervision: HE and HI. Writing of the original draft: $\mathrm{HN}$ and $\mathrm{KY}$ and manuscript review and editing: $\mathrm{HI}$.

\section{Acknowledgements}

The Authors would like to thank all medical staff in our hospital for their support. This work was partly granted by Hyogo Innovative Challenge, Hyogo college of medicine, Japan.

\section{References}

1 Dasarathy S and Merli M: Sarcopenia from mechanism to diagnosis and treatment in liver disease. J Hepatol 65(6): 12321244, 2016. PMID: 27515775. DOI: 10.1016/j.jhep.2016.07.040

2 Nishikawa H, Enomoto H, Yoh K, Iwata Y, Sakai Y, Kishino K, Ikeda N, Takashima T, Aizawa N, Takata R, Hasegawa K, Ishii $\mathrm{N}$, Yuri Y, Nishimura T, Iijima H and Nishiguchi S: Combined albumin-bilirubin grade and skeletal muscle mass as a predictor in liver cirrhosis. J Clin Med 8(6): pii: E782, 2019. PMID: 31159435. DOI: $10.3390 / \mathrm{jcm} 8060782$

3 Nishikawa H, Enomoto H, Yoh K, Iwata Y, Sakai Y, Kishino K, Ikeda N, Takashima T, Aizawa N, Takata R, Hasegawa K, Ishii N, Yuri Y, Nishimura T, Iijima $H$ and Nishiguchi S: Healthrelated quality of life in chronic liver diseases: A strong impact of hand grip strength. J Clin Med 7(12): pii: E553, 2018. PMID: 30558298. DOI: $10.3390 / \mathrm{jcm} 7120553$

4 Aby ES and Saab S: Frailty, sarcopenia, and malnutrition in cirrhotic patients. Clin Liver Dis 23(4): 589-605, 2019. PMID: 31563213. DOI: 10.1016/j.cld.2019.06.001

5 Williams FR, Berzigotti A, Lord JM, Lai JC and Armstrong MJ: Review article: impact of exercise on physical frailty in patients with chronic liver disease. Aliment Pharmacol Ther 50(9): 9881000, 2019. PMID: 31502264. DOI: 10.1111/apt.15491

6 Ebadi M, Bhanji RA, Mazurak VC, Montano-Loza AJ: Sarcopenia in cirrhosis: from pathogenesis to interventions. J Gastroenterol 54(10): 845-859, 2019. PMID: 31392488. DOI: 10.1007/s00535-019-01605-6

7 Ooi PH, Hager A, Mazurak VC, Dajani K, Bhargava R, Gilmour SM, Mager DR: Sarcopenia in Chronic Liver Disease: Impact on Outcomes. Liver Transpl 25(9): 1422-1438, 2019. PMID: 31242345. DOI: 10.1002/lt.25591

8 Hsu CS and Kao JH: Sarcopenia and chronic liver diseases. Expert Rev Gastroenterol Hepatol 12(12): 1229-1244, 2018. PMID: 30791794. DOI: 10.1080/17474124.2018.1534586

9 Nardelli S, Gioia S, Faccioli J, Riggio O and Ridola L: Sarcopenia and cognitive impairment in liver cirrhosis: A viewpoint on the clinical impact of minimal hepatic encephalopathy. World J Gastroenterol 25(35): 5257-5265, 2019. PMID: 31558871. DOI: 10.3748/wjg.v25.i35.5257

10 Wijarnpreecha K, Werlang M, Panjawatanan P, Kroner PT, Cheungpasitporn W, Lukens FJ, Pungpapong S and Ungprasert P: Association between sarcopenia and hepatic encephalopathy: A systematic review and meta-analysis. Ann Hepatol 19(3): 245250, 2020. PMID: 31422030. DOI: 10.1016/j.aohep.2019.06.007

11 Kitajima Y, Takahashi H, Akiyama T, Murayama K, Iwane S, Kuwashiro T, Tanaka K, Kawazoe S, Ono N, Eguchi T, Anzai K and Eguchi Y: Supplementation with branched-chain amino acids ameliorates hypoalbuminemia, prevents sarcopenia, and reduces fat accumulation in the skeletal muscles of patients with liver cirrhosis. J Gastroenterol 53(3): 427-437, 2018. PMID: 28741271. DOI: 10.1007/s00535-017-1370-x

12 Namba M, Hiramatsu A, Aikata H, Kodama K, Uchikawa S, Ohya K, Morio K, Fujino H, Nakahara T, Murakami E, Yamauchi M, Kawaoka T, Tsuge M, Imamura M and Chayama $\mathrm{K}$ : Management of refractory ascites attenuates muscle mass reduction and improves survival in patients with decompensated cirrhosis. J Gastroenterol 55(2): 217-226, 2020. PMID: 31485782. DOI: 10.1007/s00535-019-01623-4

13. Hiraoka A, Aibiki T, Okudaira T, Toshimori A, Kawamura T, Nakahara H, Suga Y, Azemoto N, Miyata H, Miyamoto Y, Ninomiya T, Hirooka M, Abe M, Matsuura B, Hiasa Y and Michitaka K: Muscle atrophy as pre-sarcopenia in Japanese patients with chronic liver disease: computed tomography is useful for evaluation. J Gastroenterol 50(12): 1206-1213, 2015. PMID: 25820219. DOI: 10.1007/s00535-015-1068-x

14 Nishikawa H, Shiraki M, Hiramatsu A, Moriya K, Hino K and Nishiguchi S: Japan Society of Hepatology guidelines for sarcopenia in liver disease (1st edition): Recommendation from the working group for creation of sarcopenia assessment criteria. Hepatol Res 46(10): 951-963, 2016. PMID: 27481650. DOI: 10.1111/hepr.12774

15 Arai H, Akishita $M$ and Chen LK: Growing research on sarcopenia in Asia. Geriatr Gerontol Int 14 Suppl 1: 1-7, 2014. PMID: 24450555. DOI: $10.1111 /$ ggi.12236 
16 Cruz-Jentoft AJ, Bahat G, Bauer J, Boirie Y, Bruyère O, Cederholm T, Cooper C, Landi F, Rolland Y, Sayer AA, Schneider SM, Sieber CC, Topinkova E, Vandewoude M, Visser $\mathrm{M}$ and Zamboni M; Writing Group for the European Working Group on Sarcopenia in Older People 2 (EWGSOP2), and the Extended Group for EWGSOP2. Sarcopenia: revised European consensus on definition and diagnosis. Age Ageing 48(1): 1631, 2019. PMID: 30312372. DOI: 10.1093/ageing/afy 169

17 Sinclair M, Gow PJ, Grossmann M and Angus PW: Review article: sarcopenia in cirrhosis--aetiology, implications and potential therapeutic interventions. Aliment Pharmacol Ther 43(7): 765-777, 2016. PMID: 26847265. DOI: 10.1111/apt. 13549

18 Lai JC, Covinsky KE, McCulloch CE and Feng S: The liver frailty index improves mortality prediction of the subjective clinician assessment in patients with cirrhosis. Am J Gastroenterol 113(2): 235-242, 2018. PMID: 29231189. DOI: 10.1038/ajg.2017.443

19 Bhanji RA, Montano-Loza AJ and Watt KD: Sarcopenia in cirrhosis: Looking beyond the skeletal muscle loss to see the systemic disease. Hepatology 70(6): 2193-2203, 2019. PMID: 31034656. DOI: 10.1002/hep.30686

20 Ribeiro AR, Howlett SE and Fernandes A: Frailty-A promising concept to evaluate disease vulnerability. Mech Ageing Dev 187: 111217, 2020. PMID: 32088282. DOI: 10.1016/j.mad.2020. 111217

21 Satake S and Arai H: Implications of frailty screening in clinical practice. Curr Opin Clin Nutr Metab Care 20(1): 4-10, 2017. PMID: 32088282. DOI: 10.1016/j.mad.2020.111217

22 Sewo Sampaio PY, Sampaio RA, Yamada M and Arai H: Systematic review of the Kihon Checklist: Is it a reliable assessment of frailty? Geriatr Gerontol Int 16(8): 893-902, 2016. PMID: 27444395. DOI: 10.1111/ggi.12833

23 Fried LP, Tangen CM, Walston J, Newman AB, Hirsch C, Gottdiener J, Seeman T, Tracy R, Kop WJ, Burke G and McBurnie MA; Cardiovascular Health Study Collaborative Research Group. Frailty in older adults: evidence for a phenotype. J Gerontol A Biol Sci Med Sci 56(3): M146-56, 2001. PMID: 11253156. DOI: 10.1093/gerona/56.3.m146

24 Satake S and Arai H: Chapter 1 Frailty: Definition, diagnosis, epidemiology. Geriatr Gerontol Int 20 Suppl 1: 7-13, 2020. PMID: 32050303. DOI: 10.1111/ggi.13830

25 Carey EJ, Steidley DE, Aqel BA, Byrne TJ, Mekeel KL, Rakela J, Vargas HE and Douglas DD: Six-minute walk distance predicts mortality in liver transplant candidates. Liver Transpl 16(12): 1373-1378, 2010. PMID: 21117246. DOI: 10.1002/ 1t. 22167

26 Goldwater DS and Pinney SP: Frailty in advanced heart failure: A consequence of aging or a separate entity? Clin Med Insights Cardiol 9(Suppl 2): 39-46, 2015. PMID: 26244037. DOI: 10.4137/CMC.S19698

27 Azoulay E, Mokart D, Kouatchet A, Demoule A and Lemiale V: Acute respiratory failure in immunocompromised adults. Lancet Respir Med 7(2): 173-186, 2019. PMID: 30529232. DOI: 10.1016/S2213-2600(18)30345-X

28 Fukui H, Saito H, Ueno Y, Uto H, Obara K, Sakaida I, Shibuya A, Seike M, Nagoshi S, Segawa M, Tsubouchi H, Moriwaki H, Kato A, Hashimoto E, Michitaka K, Murawaki T, Sugano K, Watanabe $M$ and Shimosegawa T: Evidence-based clinical practice guidelines for liver cirrhosis 2015. J Gastroenterol
51(7): 629-650, 2016. PMID: 27246107. DOI: 10.1007/s00535016-1216-y

29 Lurie Y, Webb M, Cytter-Kuint R, Shteingart S and Lederkremer GZ: Non-invasive diagnosis of liver fibrosis and cirrhosis. World J Gastroenterol 21(41): 11567-11583, 2015. PMID: 26556987. DOI: $10.3748 /$ wjg.v21.i41.11567

30 Zarski JP, Sturm N, Guechot J, Paris A, Zafrani ES, Asselah T, Boisson RC, Bosson JL, Guyader D, Renversez JC, Bronowicki JP, Gelineau MC, Tran A, Trocme C, De Ledinghen V, Lasnier E, Poujol-Robert A, Ziegler F, Bourliere M, Voitot H, Larrey D, Rosenthal-Allieri MA, Fouchard HI, Bailly F and Vaubourdolle M; ANRS HCEP 23 Fibrostar Group. Comparison of nine blood tests and transient elastography for liver fibrosis in chronic hepatitis C: the ANRS HCEP-23 study. J Hepatol 56(1): 55-62, 2012. PMID: 21781944. DOI: $10.1016 /$ j.jhep.2011.05.024

31 Romanelli RG and Stasi C: Recent advancements in diagnosis and therapy of liver cirrhosis. Curr Drug Targets 17(15): 18041817, 2016. PMID: 27296314. DOI: 10.2174/ 1389450117666160613101413

32 Nishikawa H, Enomoto H, Ishii A, Iwata Y, Miyamoto Y, Ishii N, Yuri Y, Takata R, Hasegawa K, Nakano C, Nishimura T, Yoh K, Aizawa N, Sakai Y, Ikeda N, Takashima T, Iijima H and Nishiguchi S: Development of a simple predictive model for decreased skeletal muscle mass in patients with compensated chronic liver disease. Hepatol Res 47(12): 1223-1234, 2017. PMID: 28019060. DOI: 10.1111/hepr.12857

33 Johnson PJ, Berhane S, Kagebayashi C, Satomura S, Teng M, Reeves HL, O’Beirne J, Fox R, Skowronska A, Palmer D, Yeo W, Mo F, Lai P, Iñarrairaegui M, Chan SL, Sangro B, Miksad R, Tada T, Kumada T and Toyoda H: Assessment of liver function in patients with hepatocellular carcinoma: a new evidence-based approach-the ALBI grade. J Clin Oncol 33(6): 550-558, 2015. PMID: 25512453. DOI: 10.1200/JCO.2014.57.9151

34 Dunn MA, Rogal SS, Duarte-Rojo A and Lai JC: Physical function, physical activity and quality of life after liver transplantation: A review. Liver Transpl 26(5): 702-708, 2020. PMID: 32128971. DOI: 10.1002/lt.25742

35 Lai JC, Covinsky KE, Dodge JL, Boscardin WJ, Segev DL, Roberts JP and Feng S: Development of a novel frailty index to predict mortality in patients with end-stage liver disease. Hepatology 66(2): 564-574, 2017. PMID: 28422306. DOI: 10.1002/hep.29219

36 Kok B, Whitlock R, Ferguson T, Kowalczewski J, Tangri N and Tandon P: Health-related quality of life: A rapid predictor of hospitalization in patients with cirrhosis. Am J Gastroenterol 115(4): 575-583, 2020. PMID: 32079859. DOI: 10.14309/ ajg.0000000000000545

37 Tapper EB: Frailty and outcomes after liver transplantation. Curr Transplant Rep 6(1): 1-6, 2019. PMID: 31602355. DOI: 10.1007/s40472-019-0222-4

38 Lai JC, Dodge JL, McCulloch CE, Covinsky KE and Singer JP: Frailty and the burden of concurrent and incident disability in patients with cirrhosis: A prospective cohort study. Hepatol Commun 4(1): 126-133, 2019. PMID: 31909360. DOI: 10.1002/ hep4.1444

39 Lai JC, Sonnenday CJ, Tapper EB, Duarte-Rojo A, Dunn MA, Bernal W, Carey EJ, Dasarathy S, Kamath BM, Kappus MR, Montano-Loza AJ, Nagai S and Tandon P: Frailty in liver transplantation: An expert opinion statement from the American Society of Transplantation Liver and Intestinal Community of 
Practice. Am J Transplant 19(7): 1896-1906, 2019. PMID: 30980701. DOI: 10.1111/ajt.15392

40 Bhanji RA, Narayanan P, Moynagh MR, Takahashi N, Angirekula M, Kennedy CC, Mara KC, Dierkhising RA and Watt KD: Differing impact of sarcopenia and frailty in nonalcoholic steatohepatitis and alcoholic liver disease. Liver Transplant 25: 14-24, 2019. PMID: 30257063. DOI: 10.1002/lt. 25346

41 Buchard B, Boirie Y, Cassagnes L, Lamblin G, Coilly A and Abergel A: Assessment of malnutrition, sarcopenia and frailty in patients with cirrhosis: Which tools should we use in clinical practice? Nutrients 12(1): pii: E186, 2019. PMID: 31936597. DOI: $10.3390 / \mathrm{nu} 12010186$

42 Fozouni L, Wang CW and Lai JC: Sex differences in the association between frailty and sarcopenia in patients with cirrhosis. Clin Transl Gastroenterol 10(12): e00102, 2019. PMID: 31789932. DOI: 10.14309/ctg.0000000000000102

43 Bunchorntavakul $\mathrm{C}$ and Reddy KR: Review article: malnutrition/sarcopenia and frailty in patients with cirrhosis. Aliment Pharmacol Ther 51(1): 64-77, 2020. PMID: 31701570. DOI: 10.1111/apt.15571

44 Kojima G, Iliffe S, Taniguchi Y, Shimada H, Rakugi H and Walters K: Prevalence of frailty in Japan: A systematic review and meta-analysis. J Epidemiol 27(8): 347-353, 2017. PMID: 28142044. DOI: $10.1016 /$ j.je.2016.09.008

45 Kok B and Tandon P: Frailty in patients with cirrhosis. Curr Treat Options Gastroenterol 16(2): 215-225, 2018. PMID: 29589278. DOI: 10.1007/s11938-018-0179-x

46 Nishikawa H, Yoh K, Enomoto H, Ishii N, Iwata Y, Nakano C, Takata R, Nishimura T, Aizawa N, Sakai Y, Ikeda N, Hasegawa $\mathrm{K}$, Takashima T, Iijima $\mathrm{H}$ and Nishiguchi S: Extracellular water to total body water ratio in viral liver diseases: A study using bioimpedance analysis. Nutrients 10(8): pii: E1072, 2018. PMID: 30103528. DOI: 10.3390/nu10081072
47 Kishino K, Enomoto H, Shimono Y, Moriwaki EI, Nishikawa H, Nishimura T, Iwata Y, Iijima $\mathrm{H}$ and Nishiguchi S: Association of an overhydrated state with the liver fibrosis and prognosis of cirrhotic patients. In Vivo 34(3): 1347-1353, 2020. PMID: 32354929. DOI: 10.21873 /invivo.11912

48 Hadjihambi A, Arias N, Sheikh M and Jalan R: Hepatic encephalopathy: a critical current review. Hepatol Int 12(Suppl 1): 135-147, 2018. PMID: 28770516. DOI: 10.1007/s12072-0179812-3

49 Ji F, Pasternak O, Liu S, Loke YM, Choo BL, Hilal S, Xu X, Ikram MK, Venketasubramanian N, Chen CL and Zhou J: Distinct white matter microstructural abnormalities and extracellular water increases relate to cognitive impairment in Alzheimer's disease with and without cerebrovascular disease. Alzheimers Res Ther 9(1): 63, 2017. PMID: 28818116. DOI: 10.1186/s13195-017-0292-4

50 Lin WC, Chou KH, Chen CL, Chen HL, Lu CH, Li SH, Huang $\mathrm{CC}$, Lin $\mathrm{CP}$ and Cheng YF: Longitudinal brain white matter alterations in minimal hepatic encephalopathy before and after liver transplantation. PLoS One 9(8): e105887, 2014. PMID: 25166619. DOI: 10.1371/journal.pone.0105887

Received May 27, 2020

Revised June 7, 2020

Accepted June 12, 2020 